\title{
Clinical Illness and Outcomes in Patients with Ebola in Sierra Leone
}

\section{Citation}

Schieffelin, John S., Jeffrey G. Shaffer, Augustine Goba, Michael Gbakie, Stephen K. Gire, Andres Colubri, Rachel S.G. Sealfon, et al. 2014. "Clinical Illness and Outcomes in Patients with Ebola in Sierra Leone." N Engl J Med 371 (22) (November 27): 2092-2100. doi:10.1056/nejmoa1411680.

\section{Published Version}

doi:10.1056/NEJMoa1411680

\section{Permanent link}

http://nrs.harvard.edu/urn-3:HUL.InstRepos:14412251

\section{Terms of Use}

This article was downloaded from Harvard University's DASH repository, and is made available under the terms and conditions applicable to Other Posted Material, as set forth at http:// nrs.harvard.edu/urn-3:HUL.InstRepos:dash.current.terms-of-use\#LAA

\section{Share Your Story}

The Harvard community has made this article openly available.

Please share how this access benefits you. Submit a story.

\section{Accessibility}




\section{Clinical Illness and Outcomes in Patients with Ebola in Sierra Leone}

\author{
J.S. Schieffelin, J.G. Shaffer, A. Goba, M. Gbakie, S.K. Gire, A. Colubri, \\ R.S.G. Sealfon, L. Kanneh, A. Moigboi,** M. Momoh, M. Fullah,* L.M. Moses, \\ B.L. Brown, K.G. Andersen, S. Winnicki, S.F. Schaffner, D.J. Park, N.L. Yozwiak, \\ P.-P. Jiang, D. Kargbo, S. Jalloh, M. Fonnie,* V. Sinnah,* I. French, A. Kovoma,* \\ F.K. Kamara, V. Tucker, E. Konuwa, J. Sellu, I. Mustapha, M. Foday, M. Yillah, \\ F. Kanneh, S. Saffa, * J.L.B. Massally, M.L. Boisen, L.M. Branco, M.A. Vandi, \\ D.S. Grant, C. Happi, S.M. Gevao, T.E. Fletcher, R.A. Fowler, D.G. Bausch, \\ P.C. Sabeti, S.H. Khan,* and R.F. Garry, for the KGH Lassa Fever Program, \\ the Viral Hemorrhagic Fever Consortium, and the WHO Clinical Response Team'-
}

ABSTRACT

\section{BACKGROUND}

Limited clinical and laboratory data are available on patients with Ebola virus disease (EVD). The Kenema Government Hospital in Sierra Leone, which had an existing infrastructure for research regarding viral hemorrhagic fever, has received and cared for patients with EVD since the beginning of the outbreak in Sierra Leone in May 2014.

\section{METHODS}

We reviewed available epidemiologic, clinical, and laboratory records of patients in whom EVD was diagnosed between May 25 and June 18, 2014. We used quantitative reverse-transcriptase-polymerase-chain-reaction assays to assess the load of Ebola virus (EBOV, Zaire species) in a subgroup of patients.

\section{RESULTS}

Of 106 patients in whom EVD was diagnosed, 87 had a known outcome, and 44 had detailed clinical information available. The incubation period was estimated to be 6 to 12 days, and the case fatality rate was $74 \%$. Common findings at presentation included fever (in $89 \%$ of the patients), headache (in 80\%), weakness (in 66\%), dizziness (in 60\%), diarrhea (in 51\%), abdominal pain (in 40\%), and vomiting (in 34\%). Clinical and laboratory factors at presentation that were associated with a fatal outcome included fever, weakness, dizziness, diarrhea, and elevated levels of blood urea nitrogen, aspartate aminotransferase, and creatinine. Exploratory analyses indicated that patients under the age of 21 years had a lower case fatality rate than those over the age of 45 years ( $57 \%$ vs. $94 \%, P=0.03$ ), and patients presenting with fewer than 100,000 EBOV copies per milliliter had a lower case fatality rate than those with 10 million EBOV copies per milliliter or more (33\% vs. $94 \%, \mathrm{P}=0.003$ ). Bleeding occurred in only 1 patient.

\section{CONCLUSIONS}

The incubation period and case fatality rate among patients with EVD in Sierra Leone are similar to those observed elsewhere in the 2014 outbreak and in previous outbreaks. Although bleeding was an infrequent finding, diarrhea and other gastrointestinal manifestations were common. (Funded by the National Institutes of Health and others.)
The authors' full names, academic degrees, and affiliations are listed in the Appendix. Address reprint requests to $\mathrm{Dr}$. Schieffelin at the Departments of Medicine and Pediatrics, Tulane University School of Medicine, 1430 Tulane Ave., TB-8, New Orleans, LA 70112, or at jschieff@tulane.edu; or to Dr. Sabeti at Harvard University Center for Systems Biology, 52 Oxford St., Cambridge, MA 02138, or at pardis@broadinstitute.org.

Dr. Schieffelin, Dr. Shaffer, Mr. Goba, Mr. Gbakie, Mr. Gire, and Dr. Colubri and Drs. Sabeti, Khan, and Garry contributed equally to this article.

* Deceased.

$\uparrow \mathrm{A}$ complete list of the members of the Kenema Government Hospital (KGH) Lassa Fever Program, the Viral Hemorrhagic Fever Consortium, and the World Health Organization (WHO) Clinical Response Team is provided in the Supplementary Appendix, available at NEJM.org.

This article was published on October 29, 2014, at NEJM.org.

DOI: 10.1056/NEJMoa1411680 Copyright (๑ 2014 Massachusetts Medical Society. 
T HE LARGEST AND MOST WIDESPREAD outbreak of Ebola virus disease (EVD) continues to spread through West Africa, with more than 10,100 cases reported in Guinea, Sierra Leone, Liberia, Senegal, Nigeria, and Mali as of October $25,2014 .{ }^{1}$ The possibility of global spread of the disease was realized recently with the diagnosis of EVD in patients in the United States and Spain. ${ }^{2}$ The EVD outbreak appears to have originated near the town of Guéckédou, which is in the forest region of Guinea and close to the borders of Sierra Leone and Liberia. ${ }^{3,4} \mathrm{Se}$ quence analyses indicated that the West African variant of Ebola virus (EBOV, Zaire species) diverged from Middle African lineages approximately a decade ago. ${ }^{5}$ Genetic similarity across the 2014 samples suggests a single introduction from an animal reservoir, with human-to-human transmission sustaining the outbreak.

EBOV infection presents many challenges to clinical management. ${ }^{6,7}$ Case fatality rates in past EVD outbreaks have ranged from 45 to $90 \%{ }^{8}$ Exposure to EBOV-infected patients is a hazard for health care providers, one that has been exacerbated by the scale of the current outbreak. There are currently no approved treatments for EVD, although supportive care, including the administration of intravenous fluids and empirical use of antibiotics, is thought to be important. Care in clinical settings that have advanced medical expertise available may increase survival by facilitating maintenance of hydration, circulatory volume, and blood pressure. ${ }^{7}$

In past outbreaks, EVD has been characterized by a constellation of signs and symptoms beginning with fever and progressing to diarrhea, vomiting, and, in a subgroup of patients, hemorrhage. ${ }^{6,9,10}$ However, the sporadic nature of EBOV outbreaks and their occurrence in remote, resource-limited settings have precluded the acquisition of extensive clinical and laboratory data. The natural history of EVD in the current outbreak may vary from that in previous outbreaks.

For the past decade, Kenema Government Hospital, located in the Eastern Province of Sierra Leone, has maintained a clinical research program on Lassa hemorrhagic fever, a viral disease that is endemic in West Africa. ${ }^{11,12}$ Because of its proximity to the epicenter of the EBOV outbreak in Guinea, the Lassa Fever Team mobilized to establish EBOV surveillance and diagnostic capabilities before entry of the virus into the country. Lassa team scientists confirmed the first cases of EVD in Sierra Leone on May 25, 2014. ${ }^{5}$ The existing infrastructure for clinical and laboratory research regarding viral hemorrhagic fever provided opportunities to evaluate EVD-associated disease. Here, we present the available data on the first 106 patients in whom EVD was diagnosed as the disease spread to Sierra Leone in order to provide a basis for understanding the clinical illness.

METHODS

\section{PATIENTS}

Before the detection of EVD in Sierra Leone, patients were referred to Kenema Government Hospital for testing and treatment if they had an illness that met the definition of a suspected Lassa case. ${ }^{11}$ After the initial cases of EVD were detected, patients were referred if they presented with an illness that met the World Health Organization case definition for EVD. ${ }^{13}$

\section{DATA COLLECTION}

All clinical and laboratory data-collection forms were being used at Kenema Government Hospital for the treatment of patients with viral hemorrhagic fever before the EVD outbreak. In addition, a blood-sampling protocol was in place to obtain specimens, if deemed appropriate by the treating physician, from all patients admitted to the ward. Demographic, clinical, and treatment data were recorded on standardized forms that were maintained outside of the ward and then were assembled and analyzed after all patients in this cohort were discharged.

\section{METABOLIC ANALYSIS}

Serum samples were analyzed with a Piccolo Blood Chemistry Analyzer and Comprehensive Metabolic Reagent Discs (Abaxis), according to the manufacturer's recommendations. We performed metabolic measurements that included the levels of sodium, potassium, total carbon dioxide, chloride, glucose, calcium, blood urea nitrogen, creatinine, alkaline phosphatase, alanine aminotransferase (ALT), aspartate aminotransferase (AST), total bilirubin, albumin, and total protein. 
EBOV DIAGNOSTICS, VIRAL LOAD, AND GENOMICS We obtained samples using the collection and processing protocols at Kenema Government Hospital under the emergency-response guidelines established by the Sierra Leone Ministry of Health and Sanitation. Diagnostic tests for the presence of EBOV were performed on site by means of quantitative reverse-transcriptase-polymerasechain-reaction (RT-PCR) assays with the use of the SuperScript III One-Step RT-PCR System with Platinum Taq DNA Polymerase (Life Technologies). EBOV RNA was quantified with the use of the Power SYBR Green RNA-to-CT 1-Step quantitative RT-PCR assay (Life Technologies) at Harvard University, as described previously. ${ }^{5}$ Amplicon concentrations were converted to EBOV copies per milliliter for quantification. We sequenced a set of $99 \mathrm{EBOV}$ isolates obtained from 78 patients and compared the results with all published EBOV sequences, as described previously. ${ }^{5}$ (All sequence data are available at the National Center for Biotechnology Information [NCBI BioGroup, PRJNA257197].)

\section{ETHICS AND BIOSAFETY REVIEW}

The institutional review board at Tulane University, the ethics committee at Harvard University, and the Sierra Leone Ethics and Scientific Review Committee approved this project. These committees waived the requirement to obtain informed consent during the West African Ebola outbreak. All clinical samples and data were collected for routine patient care and for public health interventions. The institutional biosafety committees at Tulane and Harvard and the Sierra Leone Ethics and Scientific Review Committee reviewed and approved biosafety protocols for this study.

\section{STATISTICAL ANALYSIS}

Multiple data sets representing EVD test results, patients' medical charts, and metabolic findings were linked to restrict the study sample to patients who had observations with EVD test results. Results of descriptive analyses are reported as frequencies, proportions, and arithmetic means and medians. We used Fisher's exact test to analyze hypotheses involving dichotomous variables. For cases in which a categorical variable was based on more than two categories, we used ordinary logistic regression to perform multiple comparisons. Hypotheses involving continuous variables were tested with the use of the KruskalWallis approach. We performed nonparametric multiple comparisons for continuous response variables by modeling their rank-ordered data values against a categorical variable classified according to comparison groups. Hypothesis tests were two-tailed, with a $\mathrm{P}$ value of less than 0.05 indicating statistical significance. Because of the observational nature of the data and the many tests that were performed, all P values should be interpreted cautiously. Statistical analyses were conducted with the use of SAS software, version 9.3 (SAS Institute).

RESULTS

\section{PATIENTS}

A total of 213 patients who had an illness that met the definition for suspected Lassa hemorrhagic fever or EVD were tested between May 25 and June 18, 2014, by means of conventional RT-PCR (Fig. S1 and Table S1 in the Supplementary Appendix, available with the full text of this article at NEJM.org). Of these patients, 106 (50\%) had positive results on testing for EBOV. The distribution of EVD according to age was bimodal, with peak incidences among children older than 15 years of age and among adults between the ages of 26 and 40 years (Fig. S2 in the Supplementary Appendix). Among confirmed cases, 59 patients $(60 \%)$ were female, including 1 pregnant woman who had a miscarriage immediately before her diagnosis. The majority of patients (92\%) originated in Kailahun District, and most of them $(82 \%)$ came from two chiefdoms in that district, Jawei and Kissi Teng (Tables S1 and S2 and Fig. S3 in the Supplementary Appendix).

Our previous sequencing studies identified three genetically distinct clusters of EBOV among patients with EVD in Sierra Leone (Fig. S3, S4, and S5 in the Supplementary Appendix). Groups of patients with identical viral genomes or groups in which genetic variation was shared among patients showed temporal, geographic, and intrapersonal relationships. These relationships allowed us to observe incubation periods of 6 to 12 days, which is similar to that observed in the outbreak overall. ${ }^{14}$ The mean $( \pm \mathrm{SE})$ time from the onset of symptoms to presentation and hospital admission was $5.7 \pm 0.5$ days (Table S3 and Fig. S6 in the Supplementary Appendix), and the 
mean time from the patient-reported onset of symptoms to death was $9.8 \pm 0.7$ days (Table S3 in the Supplementary Appendix). Patients who survived EVD were discharged after a mean duration of illness of $21.3 \pm 2.6$ days and a mean hospital stay of $15.3 \pm 3.1$ days. Discharge occurred when a patient was asymptomatic for at least 48 hours and blood samples were negative for EBOV on RT-PCR assay.

An overall case fatality rate of $74 \%$ was observed among the 87 patients with a known outcome. Survival outcomes could not be determined for 19 patients because they could not be contacted after providing an initial blood sample, they died before arrival at Kenema Government Hospital, or they were lost to follow-up. Patients who were younger than 21 years of age had a significantly lower case fatality rate than did patients older than 45 years of age $(57 \%$ vs. $94 \%, P=0.03$ (Fig. $1 \mathrm{~A}$, and Table S2 in the Supplementary Appendix). Patients between the ages of 21 and 45 years had an intermediate case fatality rate of $74 \%$. There was no significant difference in the case fatality rate between males and females ( $73 \%$ and $75 \%$, respectively).

\section{VIRAL LOAD}

We determined the viral load of EBOV at the time of presentation in 65 patients with a known out-

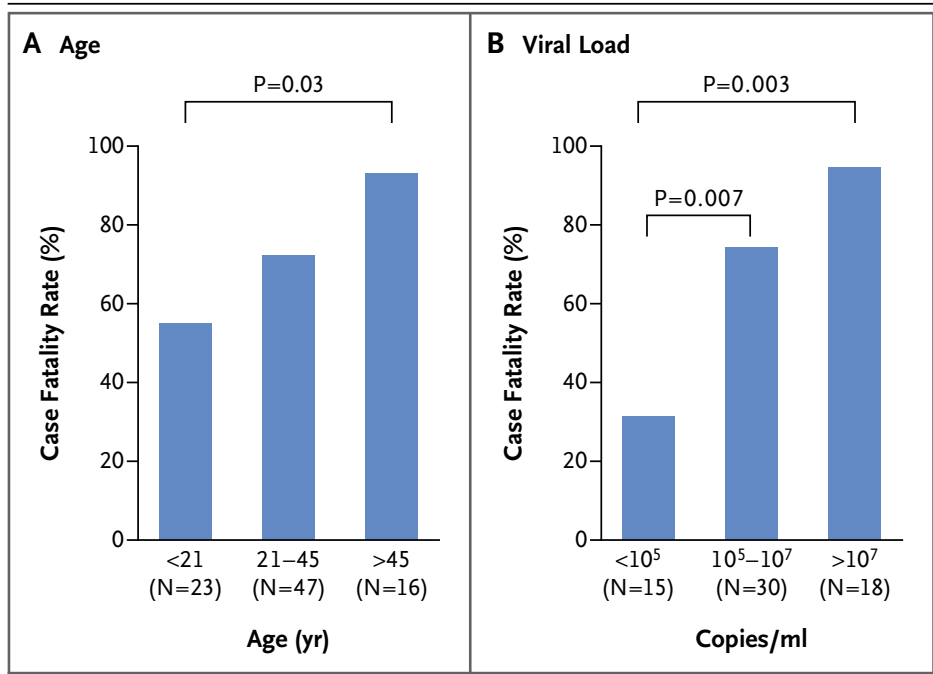

Figure 1. Case Fatality Rates among Patients with Ebola Virus Disease (EVD) in Sierra Leone.

Shown are case fatality rates among patients with confirmed EVD, a known outcome, and available data, according to age and viral load. come by means of quantitative RT-PCR. A positive correlation was noted between the viral load and the risk of death. Patients who presented with fewer than 100,000 EBOV copies per milliliter of serum had a case fatality rate of $33 \%$, whereas those with a viral load of 10 million EBOV copies per milliliter or more had a significantly higher case fatality rate of $94 \%(\mathrm{P}=0.003)$ (Fig. 1B, and Table S2 in the Supplementary Appendix). Viral loads were quantified for a limited number of patients at multiple times during their hospitalization, with results suggesting that an inability to clear the virus was a risk factor for death, even though some patients with prolonged viremia survived (Fig. S7 in the Supplementary Appendix).

\section{SYMPTOMS, VITAL SIGNS, PHYSICAL FINDINGS, AND TREATMENT}

Data regarding signs and symptoms in patients at the time of presentation were available for 44 of 106 patients (Table S4 in the Supplementary Appendix). Although biased by the case definition, common findings included fever (in $89 \%$ of the patients), headache (in $80 \%$ ), weakness (in $66 \%$ ), dizziness (in 60\%), diarrhea (in 51\%), abdominal pain (in $40 \%$ ), sore throat (in 34\%), vomiting (in 34\%), and conjunctivitis (in 31\%) (Fig. 2, and Table S5 in the Supplementary Appendix). The only symptoms that were significantly associated with a fatal outcome were weakness $(\mathrm{P}=0.003)$, dizziness $(\mathrm{P}=0.01)$, and diarrhea $(\mathrm{P}=0.04)$. Among patients with diarrhea, $94 \%$ died, whereas only $65 \%$ of those without diarrhea on presentation died. Evidence of bleeding was noted in only 1 patient. None of the other 43 patients were reported to have hemorrhagic signs during their hospital stays, but the possibility cannot be definitively excluded because of the limited charting.

Vital signs were recorded at presentation and every 6 hours thereafter. A fever (temperature, $>38.4^{\circ} \mathrm{C}\left[101.1^{\circ} \mathrm{F}\right]$ ) was recorded at the time of initial presentation in $13 \%$ of the patients, whereas a temperature of $38^{\circ} \mathrm{C}\left(100.4^{\circ} \mathrm{F}\right)$ or more was noted in $29 \%$. Temperature was the only vital sign that correlated with survival (Fig. 3A, and Table S6 in the Supplementary Appendix). The mean temperature at the time of admission was significantly higher among patients who died than among those who survived $\left(37.5^{\circ} \mathrm{C}\left[99.5^{\circ} \mathrm{F}\right]\right.$ 
vs. $\left.35.9^{\circ} \mathrm{C}\left[96.6^{\circ} \mathrm{F}\right], \mathrm{P}=0.001\right)$. A review of all vital signs that were recorded showed that 20 patients had at least one temperature reading of $38.3^{\circ} \mathrm{C}$ or more during their hospital course. All but 5 patients met the criteria for relative bradycardia, with a mean temperature of $38.9 \pm 0.5^{\circ} \mathrm{C}$ $\left(102.0 \pm 32.9^{\circ} \mathrm{F}\right)$ and a mean heart rate of $87 \pm 17.8$ beats per minute (Fig. S8 in the Supplementary Appendix). ${ }^{15}$ There were no significant differences between case patients with fatal EVD and those with nonfatal EVD with respect to other vital signs (Fig. 3B through 3F).

All 44 patients were given intravenous fluids. Four of the patients $(9 \%)$ received antimalarial and antibacterial drugs before referral for EBOV testing. During their hospitalization on the viral hemorrhagic fever ward, $55 \%$ of the patients received antimalarial drugs and $93 \%$ received antibacterial drugs (Table S7 in the Supplementary Appendix). The most commonly administered antibiotic was ceftriaxone (in $80 \%$ of patients). Patients also received ampicillin (16\%), metronidazole (14\%), and ciprofloxacin (5\%). Several patients received more than one antibacterial agent. A total of $27 \%$ of patients were also treated with paracetamol.

\section{METABOLIC TESTING}

At the time of presentation, abnormalities in several metabolic measurements were accurate predictors of the EVD diagnosis. Significant elevations in blood urea nitrogen, creatinine, AST, ALT, and alkaline phosphatase were noted among patients with EVD, as compared with febrile patients who were EBOV-negative and healthy volunteers (Table S8 and Fig. S9 in the Supplementary Appendix). EBOV-negative patients, many of whom had malaria or other febrile illnesses and were seriously ill, had lower levels of total carbon dioxide and higher AST and ALT levels than did healthy volunteers. High levels of creatinine, blood urea nitrogen, and AST were significantly associated with a fatal EVD outcome (Fig. 4, and Tables S9 and S10 in the Supplementary Appendix). There was no significant difference between patients with fatal cases and those with nonfatal cases in other metabolic measures at presentation, including levels of total carbon dioxide, alkaline phosphatase, and ALT.

Analysis of metabolic measures in patients for whom more than one blood sample was ob-

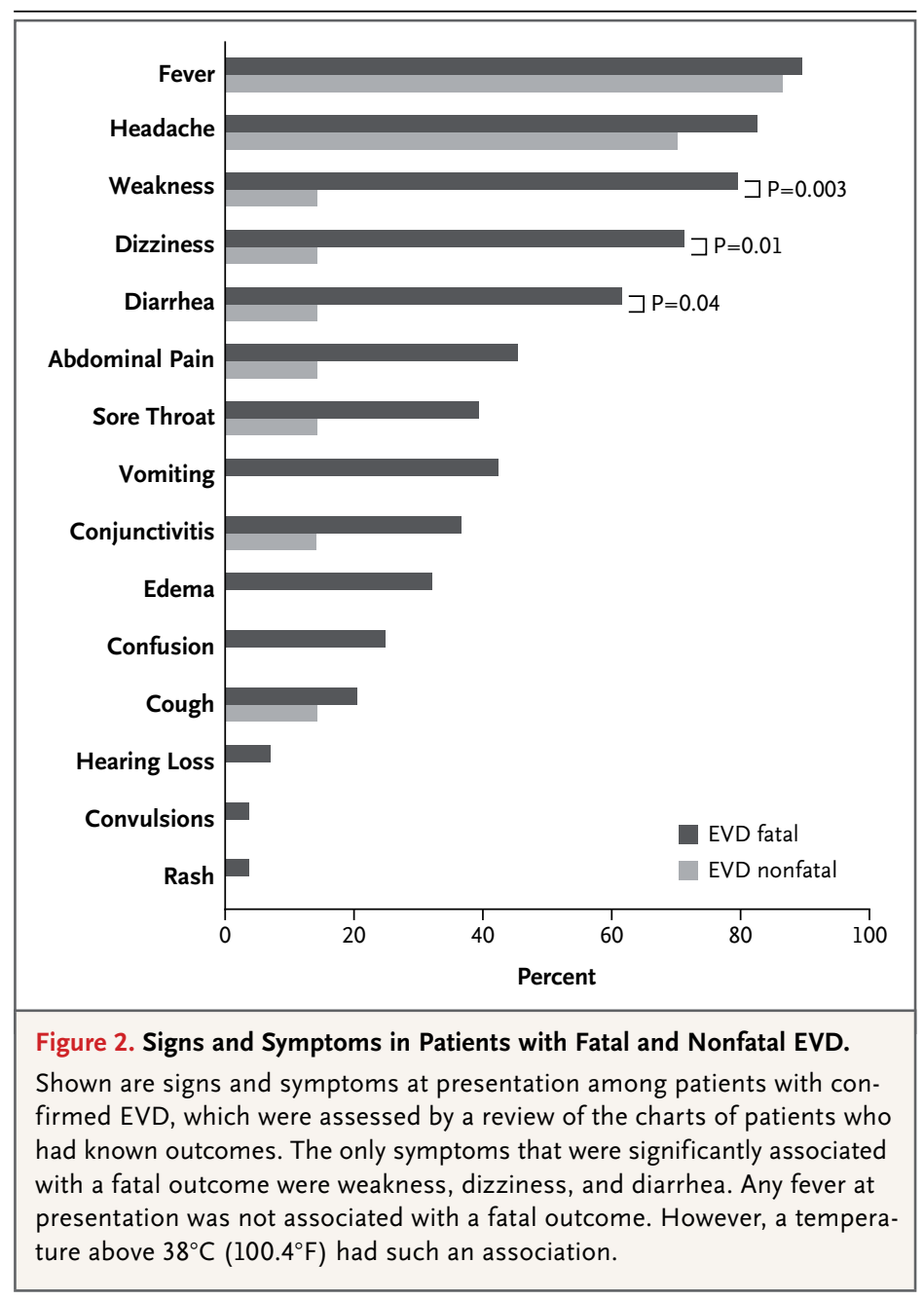

tained showed that normal or decreasing levels of blood urea nitrogen, creatinine, alkaline phosphatase, ALT, and AST and normal or increasing levels of total carbon dioxide heralded recovery (Fig. S10 in the Supplementary Appendix). Most patients who died from EVD had acidosis on admission or acidosis that developed during hospitalization. Among patients who died, levels of blood urea nitrogen and creatinine progressively increased over time, suggesting that dehydration and worsening renal function played a significant role in their hospital course. Patients who died were more likely to have sustained elevations in AST, ALT, or alkaline phosphatase (especially AST) than were patients who survived. Total bilirubin was mildly elevated in only one patient who died, suggesting that hemolysis and hepatic failure are not major components of EVD. 


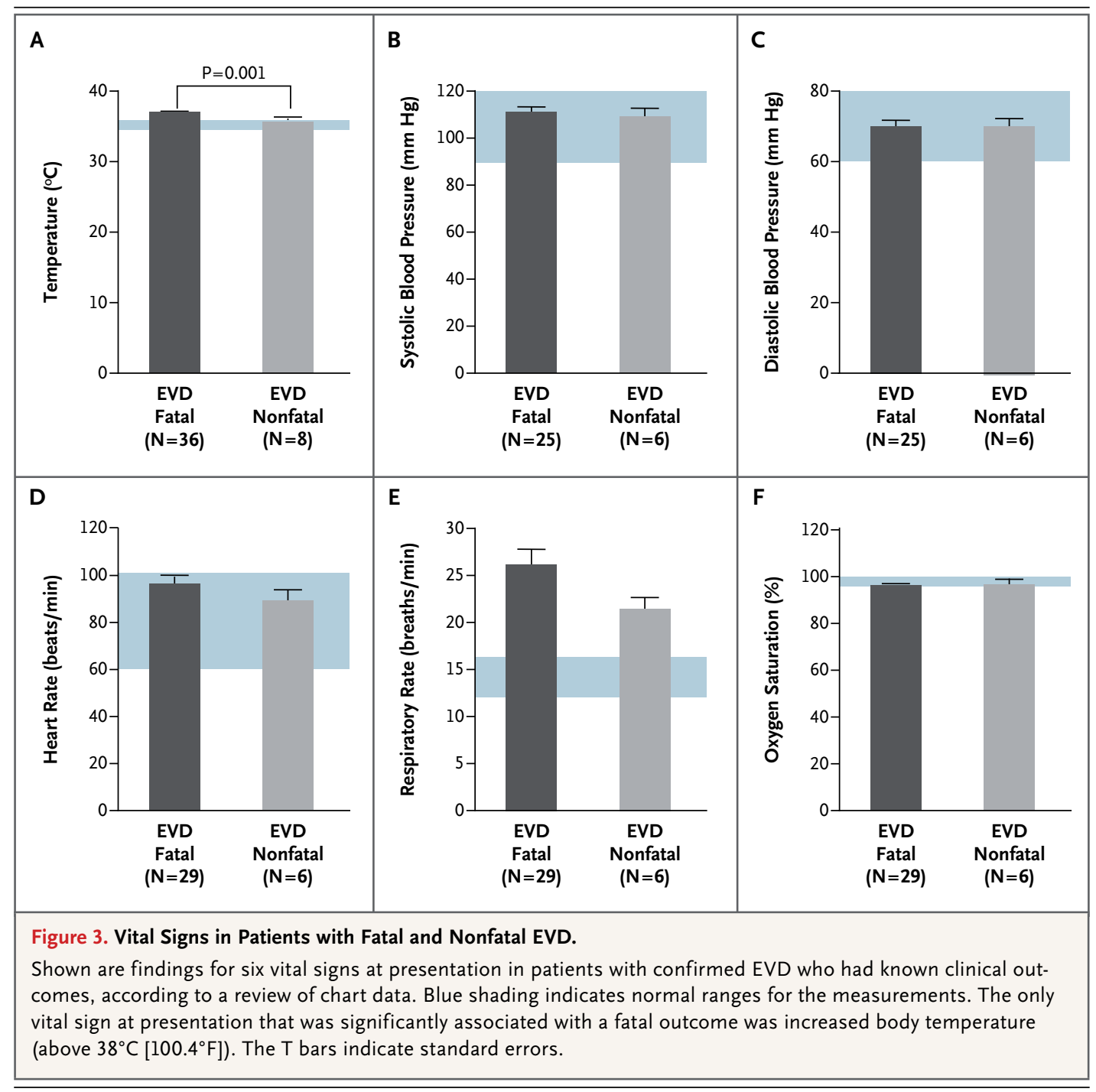

\section{DEVELOPMENT OF A SCORING SYSTEM}

Scoring systems, such as the modified Acute Physiology and Chronic Health Evaluation (APACHE), have been used in resource-limited settings as prognostic indicators. ${ }^{16,17}$ Although such a system for the evaluation of EVD would require validation before it could be used, it may be possible to develop a system similar to APACHE to predict the risk of death with the use of clinical data that are available on presentation. Other measures that were found to differ significantly between patients with fatal EVD and those with nonfatal EVD are shown in Table S11 in the Supplementary Appendix.

\section{DISCUSSION}

At Kenema Government Hospital, the research infrastructure was already in place to allow for data collection at the beginning of the EVD outbreak in Sierra Leone. In this retrospective analysis of the viral and clinical characteristics of the patients with EVD, several demographic and clinical characteristics were associated with a fatal outcome, including an age of more than 45 years. The effect of age on EVD has been noted in past outbreaks and remains a feature of the disease that has emerged in West Africa. ${ }^{18}$ A low virus load at presentation was associated with a 


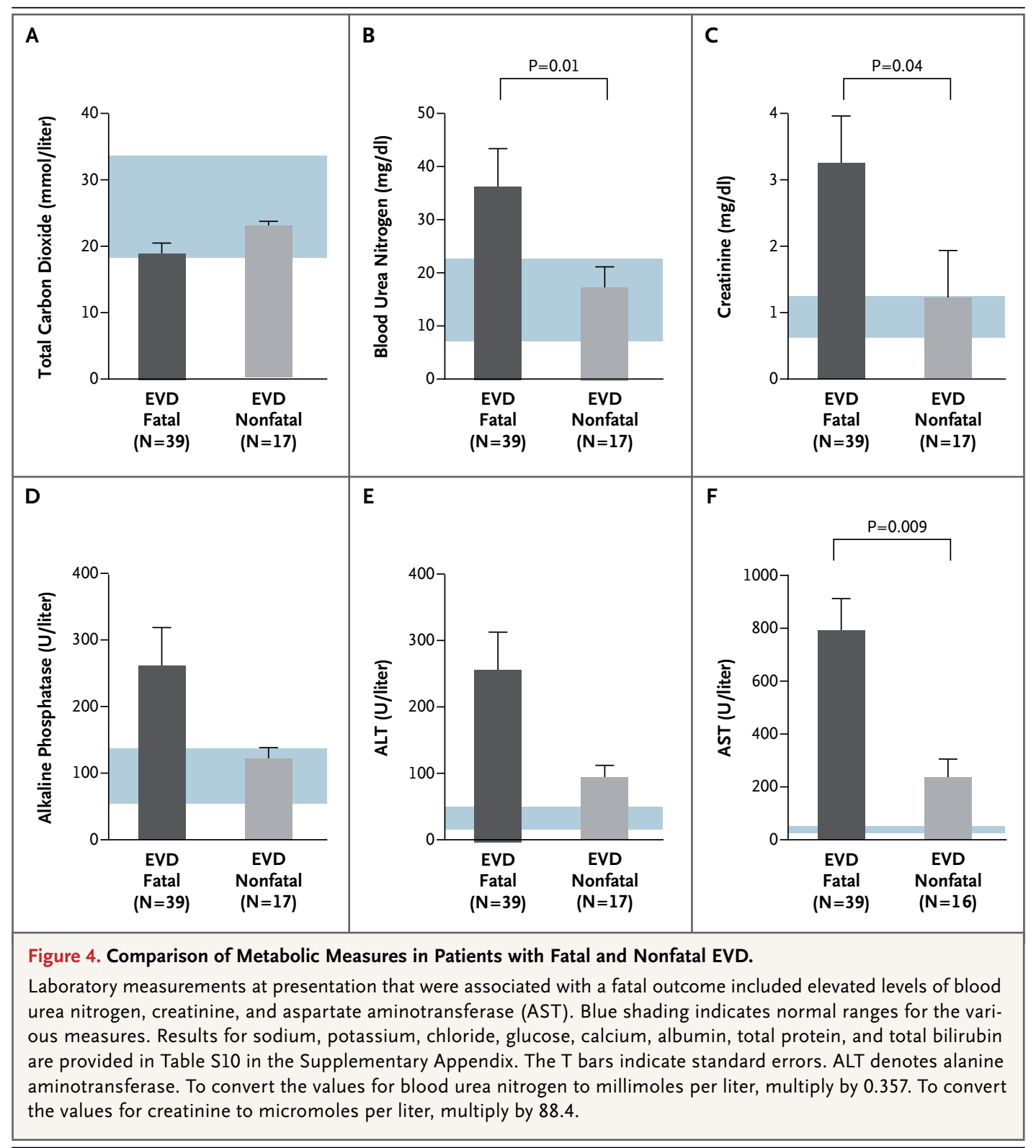

nonfatal outcome. Nearly all the patients with EVD who presented to Kenema Government Hospital had a recent history of fever. A documented fever (temperature, $>38^{\circ} \mathrm{C}\left[100.4^{\circ} \mathrm{F}\right]$ ), weakness, dizziness, and diarrhea on presentation were also associated with a fatal outcome. A number of dysfunctional hematologic and blood-system features have been described in experimental animals infected with EBOV. ${ }^{19,20}$ Only 1 of 106 patients in our study cohort had overt bleeding at presentation. Although bleeding has been noted in previous outbreaks, our results show that this symptom is rare in the current outbreak. ${ }^{14}$ As in past EVD outbreaks, ${ }^{21,22}$ we observed clotting abnormalities, including vaginal bleeding in pregnant women, hematemesis, and oozing at intravenous catheter sites, which require further investigation (data not shown).

We found evidence of hepatocellular damage and impaired kidney function, as assessed on metabolic testing at presentation, in patients who died of EVD as well as in those who survived. 
However, increased deviation from normal values predicted a fatal outcome. As in previous studies, AST values were consistently higher than ALT values, which suggests that tissue damage, including rhabdomyolysis, may play a role in EVD. ${ }^{23}$ Future studies should include measurement of creatine kinase levels. Patients who recovered from the illness had normalization of levels of liver enzymes, creatinine, total carbon dioxide, blood urea nitrogen, and other markers, often over the span of a few days.

At Kenema Government Hospital, all the patients were treated by staff members who were experienced in the care of patients with viral hemorrhagic fever, and all the patients received intravenous fluids and other supportive care. Because local staff members had expertise in managing viral hemorrhagic fever, they were willing to provide clinical care for highly infectious patients and undertake invasive procedures that provided the basis for this data set. As the EVD outbreak in West Africa continues to spread on an unprecedented scale, the challenge of providing the most effective patient care is compounded. The handling of diarrhea and vomitus, which can contain infectious EBOV, ${ }^{24}$ poses a threat of infection to health care workers and cleaners, and precautions should be emphasized in preventive training. However, it is incumbent on health care professionals to ensure that EVD facilities are focused on treating and improving the survival of patients, rather than merely on providing a setting for quarantine. The clinical and laboratory findings that we describe here should provide some insight for the rational design of clinical strategies aimed at improving care in this and future EVD outbreaks.

Supported by grants from the National Institutes of Health (P20GM103501, to Dr. Schieffelin; GM080177, to Ms. Winnicki; 1U01HG007480-01, to Dr. Happi; 1DP2OD006514-01 and HHSN272201000022C, to Dr. Sabeti; and HHSN272200900049C, 1U19AI109762, 1R01AI104621, and 2R44AI088843, to Dr. Garry), the Graduate Research Fellowship Program of the National Science Foundation (to Ms. Sealfon), and the World Bank (to Dr. Happi).

Disclosure forms provided by the authors are available with the full text of this article at NEJM.org.

This article is dedicated to six of our coauthors who contributed greatly to public health and research efforts in Sierra Leone - Alex Moigboi, Mohammed Fullah, Mbalu Fonnie, Vandi Sinnah, Alice Kovoma, and S. Humarr Khan - and who died of EVD before this article could be published; and to Sidiki Saffa, who also died during the course of this work from a non-EVD illness.

We thank the Office of the President of Sierra Leone (President E. Koroma and M. Jones), Sierra Leone Ministry of Health and Sanitation (Hon. Minister A.B. Fofonah, B. Kargbo, A. Jambai), the Kenema District Health Management Team and Kenema Government Hospital for their efforts in outbreak response; Leslie Gaffney for assistance in the preparation of the original figures; and colleagues and laboratory staff members N. Wauquier, J. Bangura, V. Lungay, L. Hensley, J. Johnson, M. Voorhees, A. O'Hearn, R. Schoepp, L. Gaffney, J. Kuhn, S.C. Sealfon, J.B. Shapiro, C. Edwards, C. Bishop, R. Yenni, L. Melnik, A. Haislip, R. Wilson, M. Charbonnet, P. Kulakosky, W. Gallaher, and S. Blyden and those associated with the laboratories of Drs. Garry, Schieffelin, and Sabeti for their technical support and feedback.

\section{APPENDIX}

The authors are as follows: John S. Schieffelin, M.D., M.S.P.H., Jeffrey G. Shaffer, Ph.D., Augustine Goba, B.Sc., Michael Gbakie, R.N., Stephen K. Gire, M.P.H., Andres Colubri, Ph.D., Rachel S.G. Sealfon, S.M., Lansana Kanneh, Alex Moigboi, R.N., ${ }^{\star}$ Mambu Momoh, Mohammed Fullah, ${ }^{\star}$ Lina M. Moses, Ph.D., Bethany L. Brown, M.S.C.S., Kristian G. Andersen, Ph.D., Sarah Winnicki, M.S., Stephen F. Schaffner, Ph.D., Daniel J. Park, Ph.D., Nathan L. Yozwiak, Ph.D., Pan-Pan Jiang, Ph.D., David Kargbo, Simbirie Jalloh, Mbalu Fonnie, R.N., ${ }^{\star}$ Vandi Sinnah, ${ }^{\star}$ Issa French, Alice Kovoma, ${ }^{\star}$ Fatima K. Kamara, R.N., Veronica Tucker, Edwin Konuwa, R.N., Josephine Sellu, R.N., Ibrahim Mustapha, Momoh Foday, Mohamed Yillah, Franklyn Kanneh, Sidiki Saffa, ${ }^{\star}$ James L.B. Massally, Matt L. Boisen, Luis M. Branco, Ph.D., Mohamed A. Vandi, M.B., Ch.B., Donald S. Grant, M.B., Ch.B., Christian Happi, Ph.D., Sahr M. Gevao, M.B., Ch.B., Thomas E. Fletcher, M.D., Robert A. Fowler, M.D., Daniel G. Bausch, M.D., M.P.H.T.M., Pardis C. Sabeti, M.D., D.Phil., S. Humarr Khan, M.B., Ch.B., ${ }^{\star}$ and Robert F. Garry, Ph.D.

$\star$ Deceased.

The authors' affiliations are as follows: the School of Medicine (J.S.S., L.M.M., R.F.G.) and the School of Public Health and Tropical Medicine (J.G.S., D.G.B.), Tulane University, New Orleans; Kenema Government Hospital (A.G., M.G., L.K., A.M., M.M., M. Fullah, D.K., S.J., M. Fonnie, V.S., I.F., A.K., F.K.K., V.T., E.K., J.S., I.M., M. Foday, M.Y., F.K., S.S., J.L.B.M., D.S.G., S.H.K.), Eastern Polytechnic College (M.M., M. Fullah), and Kenema District Health Management Team, Ministry of Health and Sanitation (M.A.V.), Kenema, and University of Sierra Leone, Freetown (S.M.G.) - all in Sierra Leone; Harvard University, Center for Systems Biology, Department of Organismic and Evolutionary Biology (S.K.G., A.C., K.G.A., S.W., S.F.S., N.L.Y., P.-P.J., P.C.S.), Broad Institute of the Massachusetts Institute of Technology (MIT) and Harvard (S.K.G., R.S.G.S., K.G.A., S.W., S.F.S., D.J.P., N.L.Y., P.-P.J., P.C.S.), and the Computer Science and Artificial Intelligence Laboratory, MIT (R.S.G.S.), Cambridge, MA; Corgenix Medical, Broomfield, CO (B.L.B., M.L.B.); Zalgen Labs, Germantown, MD (L.M.B.); Redeemer's University, Redemption City, Nigeria (C.H.); Liverpool School of Tropical Medicine, Liverpool, United Kingdom (T.E.F.); University of Toronto, Toronto (R.A.F.); and U.S. Naval Medical Research Unit No. 6, Lima, Peru (D.G.B.).

REFERENCES

1. World Health Organization. Ebola response roadmap situation report. October 25, 2014 (http://www.who.int/csr/disease/ ebola/situation-reports/en).
2. McCarthy M. Ebola is diagnosed in traveler to US. BMJ 2014;349:g5980.

3. Baize S, Pannetier D, Oestereich L, et al. Emergence of Zaire Ebola virus disease in Guinea. N Engl J Med 2014;371:141825.

4. Bausch DG, Schwarz L. Outbreak of Ebola virus disease in Guinea: where ecol- 
ogy meets economy. PLoS Negl Trop Dis 2014;8(7):e3056.

5. Gire SK, Goba A, Andersen KG, et al. Genomic surveillance elucidates Ebola virus origin and transmission during the 2014 outbreak. Science 2014;345:136972.

6. Kortepeter MG, Bausch DG, Bray M. Basic clinical and laboratory features of filoviral hemorrhagic fever. J Infect Dis 2011;204:Suppl 3:S810-S816.

7. Fowler RA, Fletcher T, Fischer WA II, et al. Caring for critically ill patients with Ebola virus disease: perspectives from West Africa. Am J Respir Crit Care Med 2014;190:733-7.

8. Kuhn JH, Dodd LE, Wahl-Jensen V, Radoshitzky SR, Bavari S, Jahrling PB. Evaluation of perceived threat differences posed by filovirus variants. Biosecur Bioterror 2011;9:361-71.

9. Ndambi R, Akamituna P, Bonnet MJ, Tukadila AM, Muyembe-Tamfum JJ, Colebunders R. Epidemiologic and clinical aspects of the Ebola virus epidemic in Mosango, Democratic Republic of the Congo, 1995. J Infect Dis 1999;179:Suppl 1: S8-S10.

10. Zaki SR, Goldsmith CS. Pathologic features of filovirus infections in humans. Curr Top Microbiol Immunol 1999, 235:97-116.

11. Khan SH, Goba A, Chu M, et al. New opportunities for field research on the pathogenesis and treatment of Lassa fever. Antiviral Res 2008;78:103-15.

12. Shaffer JG, Grant DS, Schieffelin JS et al. Lassa fever in post-conflict Sierra Leone. PLoS Negl Trop Dis 2014;8(3):e2748.

13. World Health Organization, Centers for Disease Control and Prevention. Case definition recommendations for Ebola or Marburg virus diseases. In: Kasolo F, Roungou JB, Perry H, eds. Technical guidelines for integrated disease surveillance and response in the African region. 2nd ed. October 2010:270-4 (http://www.afro .who.int/en/clusters-a-programmes/dpc/ integrated-disease-surveillance/features/ 2775-technical-guidelines-for-integrated -disease-surveillance-and-response-in-the -african-region.html).

14. WHO Ebola Response Team. Ebola virus disease in West Africa - the first 9 months of the epidemic and forward projections. N Engl J Med 2014;371:148195.

15. Cunha BA. The diagnostic significance of relative bradycardia in infectious disease. Clin Microbiol Infect 2000;6:633-4. 16. Adesunkanmi ARK, Oseni SA, Adejuyigbe O, Agbakwuru EA. Acute generalized peritonitis in African children: assessment of severity of illness using modified APACHE II score. ANZ J Surg 2003;73: 275-9.

17. Adesunkanmi ARK, Badmus TA, Fadiora FO, Agbakwuru EA. Generalized peritonitis secondary to typhoid ileal perforation: assessment of severity using modified APACHE II score. Indian J Surg 2005;67:29-33.

18. Sadek RF, Khan AS, Stevens G, Peters CJ, Ksiazek TG. Ebola hemorrhagic fever,
Democratic Republic of the Congo, 1995: determinants of survival. J Infect Dis 1999; 179:Suppl 1:S24-S27.

19. Bray M, Hatfill S, Hensley L, Huggins JW. Haematological, biochemical and coagulation changes in mice, guinea-pigs and monkeys infected with a mouseadapted variant of Ebola Zaire virus. J Comp Pathol 2001;125:243-53.

20. Fisher-Hoch SP, Platt GS, Lloyd G, Simpson DI, Neild GH, Barrett AJ. Haematological and biochemical monitoring of Ebola infection in rhesus monkeys: implications for patient management. Lancet 1983;2:1055-8.

21. Geisbert TW, Young HA, Jahrling PB, Davis KJ, Kagan E, Hensley LE. Mechanisms underlying coagulation abnormalities in ebola hemorrhagic fever: overexpression of tissue factor in primate monocytes/macrophages is a key event. J Infect Dis 2003;188:1618-29.

22. Ebola haemorrhagic fever in Zaire, 1976. Bull World Health Organ 1978;56: 271-93.

23. Rollin PE, Bausch DG, Sanchez A. Blood chemistry measurements and Ddimer levels associated with fatal and nonfatal outcomes in humans infected with Sudan Ebola virus. J Infect Dis 2007; 196:Suppl 2:S364-S371.

24. Bausch DG, Towner JS, Dowell SF, et al. Assessment of the risk of Ebola virus transmission from bodily fluids and fomites. J Infect Dis 2007;196:Suppl 2: S142-S147.

Copyright (C) 2014 Massachusetts Medical Society. 